ORIGINAL RESEARCH ARTICLE

\title{
Choice of device to view video lectures: an analysis of two independent cohorts of first-year university students
}

\author{
Jesca Namuddu and Paul N. Watts* \\ School of Health, Sport and Bioscience, University of East London, London, United Kingdom \\ (Received: 16 August 2019; Revised: 24 December 2019; Accepted: 14 January 2020; \\ Published: 5 February 2020)

\begin{abstract}
Video lectures and mobile learning devices have become prominent, but little is known about device choices for watching video lectures. The setting for this study, a university that provided perpetual access to personal computers and free tablet devices to all first-year students, provided a unique opportunity to study device choice in a setting where both tablets and personal computers were perpetually available. Weekly video lectures on a first-year module were made from October to April in two independent cohorts of students. YouTube analytics were used to record data on device usage for video lecture views. Tablets were initially used for almost $70 \%$ of views. However, tablet usage declined throughout the academic year, and tablets were overtaken by personal computers as the preferred device in the second half of the academic year. Findings suggest that an initial preference for using tablets to view video lectures lasts only a few months.
\end{abstract}

Keywords: tablet; mobile learning; video lectures; University education; mobile technology

\section{Introduction}

The use of digital technology for delivering learning materials to students at higher education institutions (HEIs) is increasingly common (Henderson, Selwyn, and Aston 2017). For example, the use of video lectures delivered online has become a widespread alternative or supplement to lectures delivered face to face (Giannakos 2013; Giannakos, Chorianopoulos, and Chrisochoides 2015; Scagnoli, Choo, and Tian 2017). Video lectures are commonly used as part of 'flipped' or 'inverted' classrooms, where online delivery of lectures before scheduled classes is used with the intention of using face-to-face teaching time for more hands-on, practical activities or discussions (O'Flaherty and Philips 2015).

The use of 'flipped' classrooms has been studied extensively (O'Flaherty and Philips 2015), but there have been fewer studies specifically on the use of video lectures as a medium for delivering programme content, or on the preferences HEI students have when receiving programme content in video form. A study on attitudes towards video lectures and their impact on programme performance by Brecht and Ogilby (2008) found that compared to traditional formats, video lectures improved perceived understanding of content, preparation for exams and preparation for formative assessment. Furthermore, compared to a control group, where video lectures

*Corresponding author. Email: p.n.watts@uel.ac.uk 
were not available, Brecht and Ogilby (2008) found that pass rates were significantly improved for students who had access to video lectures. Giannakos, Jaccheri, and Krogstie (2016) found that video lectures can enhance the perceived value of teaching and learning, particularly at advanced levels. However, the author's findings also suggested that video lectures should be incorporated into HEI programmes during the first year of study to engage students with the positive use of video lectures as early as possible. Kennedy et al. (2008) also found that first-year students are more likely to engage with digital technology to receive programme materials, but when introduced to technology beyond those frequently used by students (e.g. personal computers, mobile phones and email), there was a greater variation in usage.

Robinson and Stubberud (2012) suggest that modern university students have become used to accessing material in almost any place at any given time. Moreover, there is evidence to suggest that both learners and educators at HEIs now expect programme materials to be delivered through digital technologies, including video lectures, and that this mode of delivery has many benefits to modern students who are advanced in multitasking and perceive mobile devices virtually as an extension of themselves (Robinson and Stubbed 2011; Vogt et al. 2010). However, there is also evidence from several studies to show that when receiving lecture content in digital form (in this case podcasts), students prefer to access online lectures through personal computers, rather than through mobile devices such as mobile phones or tablets (Anderson 2011; O’Bannon et al. 2011; Walls et al. 2010).

Tablets and mobile phones are alternatives to personal computers for accessing learning materials (Fabian and Maclean 2014; Kinash, Brand, and Mathew 2012). However, there has been very little research on the devices HEI students prefer to use for accessing materials, including video lectures (Byrne-Davis et al. 2015). Kinash, Brand, and Mathew (2012) found that most students had no strong preferences when asked if they preferred to access a virtual learning environment using a tablet or personal computer. Furthermore, most students responded neutrally when asked if tablet-based learning had improved learning or motivation to learn when compared to learning using personal computers.

Personal access to mobile learning devices, such as tablets - and the associated costs to HEI students - is an important consideration when researching students' preferences and choices for accessing video lectures. The widespread use of video lectures and requirements for students to access materials online may disadvantage students who do not have access to devices such as tablets, laptops or personal computers when not on campus. Some universities in the United Kingdom and the United States have used 'free' tablet devices for HEI students as a method of ensuring students have mobile access to programme materials at all times, with the intention of creating a 'level playing field' for students accessing learning materials online (Coughlan 2014).

Previous studies that have examined student's device preferences and choices have often used qualitative methods or relied on self-reports, rather than objective measures of device usage. However, a small number of studies have reported objectively measured device use. Delaviz and Ramsay (2018) use collected objective data on device preference for short instructional videos at a Canadian HEI. The authors reported that in three consecutive years (2016 to 2018), approximately $95 \%$ of these videos were viewed using personal computers. Tablets were used for only around 3\% of views each year. Gafni and Filin (2015) collected objective data on device use for viewing video lectures through an online learning platform at 15 institutions across 
three countries (United States, United Kingdom and Australia). Similarly, personal computers were used for the majority of video views ( $88 \%$ in the United Kingdom). Overall use of tablets to view videos was lower in the United Kingdom (5\%) than in the United States (11\%) and Australia (12\%). The authors also reported that the proportion of videos that were watched to completion was slightly higher for personal computers than for tablets or mobile phones. Gafni and Geri (2015) studied device use to view online videos at an HEI in Israel and found that tablet use increased from just $1.6 \%$ at the beginning of the course to $3.3 \%$ at the end of the course.

Herala et al. (2017) reported similar levels of tablet use for online video lecture views at a HEI in Finland, finding that only $5 \%$ of video views were made using tablets. The study also reported no difference in average viewing time when views were made on personal computers, mobile phones or tablets. Miner and Stefaniak (2018) conducted a survey of device preference for viewing video lectures at a large mid-Atlantic HEI in the United States. Self-reported data from 37 students suggested that $76 \%$ of students would choose to use a laptop or desktop personal computer to view video lectures as their primary device. Eleven per cent of respondents reported that they would choose tablets as the primary device for viewing video lectures. A study at the Norwegian University of Science and Technology found that only 1 out of 40 students surveyed used a tablet to view video lectures (Giannakos, Jaccheri, and Krogstie 2016).

A limitation of previous studies has been that device choice has been examined when not all students have open access to both mobile devices (i.e. tablets) and personal computers. Therefore, these studies may be susceptible to confounding by demographic and socio-economic factors related to device access. The setting for this study is an HEI that provided a 'free' personal tablet device to all level 4 students and 24-h, 7- day a week access to desktop and/or laptop personal computers on campus. This setting provides a unique opportunity to investigate device choice for viewing video lectures without bias from factors influencing access to devices.

The aim of this study is to address the following research questions: (1) What is the preferred device to view video lectures for level 4 HEI students who have access to both tablets and personal computers? (2) Does choice of device use change throughout the academic year? (3) Does viewing behaviour, such as the duration of views and the proportion of each video viewed, vary by device choice?

\section{Materials and methods}

\section{Setting and population}

The setting for this study was an HEI in London, United Kingdom, at which all level 4 (first-year undergraduate) students were provided with a new tablet device (which is theirs to keep) at induction and had 24-h a day/7-day a week access to computers through the university computer centres and library. The population for this study is two separate cohorts of students registered on a level 4 'Introduction to research methods' module on which weekly video lectures were used to supplement in-class activities. This 30 credit module ran over 24 weeks for 106 students from the beginning of October to mid-May in 2016-2017 and for 71 students from the beginning of October to the end of April in 2017-18. There were weeks with no videos or in-class activities during the Christmas, New year and Easter periods. 


\section{Video lectures}

A total of 21 video lectures were made available to students throughout the academic year. Videos were made available week by week as the content was covered on the module. For example, a video on an introductory topic at the beginning of term would be available from October to May, and a video on a topic covered later in the term would be available only from March to May. The video content covered key introductory topics on research methods for health-related programmes of study such as introduction to study designs, approaches to sampling, data collection and data analysis. The mean video duration was $28 \mathrm{~min}$ (range 15 to $46 \mathrm{~min}$ ). The same videos were made available to each cohort at approximately the same time during the academic year.

\section{Data collection}

Video lectures were made available by providing links to 'unlisted' YouTube videos through a virtual learning environment. 'Unlisted' videos cannot be accessed by searches on YouTube and are only available to those who have been provided with a direct link. YouTube Analytics API (Google 2018) is a tool provided for free by Google to anyone with a YouTube account. The tool enables users who have uploaded videos to access detailed statistics on the frequency of video views, and data on the average length and proportion of views for individual videos or groups of videos. Data are also available on the type of device used to view videos. This was the main outcome of interest in this study. For all videos made available to students on this module, YouTube Analytics was used to access data on the type of device used to view all video lectures (tablet, personal computer, mobile phone or television). In addition, for each device type, data were accessed on: total views, average views per video (and range), total view time, average view duration and average proportion of the video viewed.

\section{Data analysis}

Data from all 21 video lectures made available throughout the academic year were combined, and data were extracted on the total number of views per month and the device used per view. Data were analysed on the two independent cohorts of students (2016-2017 and 2017-2018) by presenting the proportion of monthly views on each device. Data on views per video, viewing time, duration and the proportion of videos viewed were summarised by device type.

\section{Ethical approval}

Ethical approval was not required for this study as no personal data was collected from individual students. Data on device usage is collected under YouTube's terms of use.

\section{Results}

The 2016-2017 and 2017-1718 cohorts consisted of 106 students and 71 students, respectively. The 2016-2017 cohort viewed video lectures a total of 2813 times during 
Table 1. Demographic characteristics of students in 2016-17 and 2017-18 cohorts.

\begin{tabular}{lcc}
\hline & $2016-2017$ Cohort & 2017-2018 Cohort \\
\hline $\begin{array}{l}\text { Number of students } \\
\text { Gender }\end{array}$ & 106 & 71 \\
Male & $8(7.5 \%)$ & $9(12.7 \%)$ \\
Female & $98(92.5 \%)$ & $62(87.3 \%)$ \\
Age groups & & \\
Under 21 & $39(36.8 \%)$ & $17(23.9 \%)$ \\
$21-24$ & $19(17.8 \%)$ & $11(15.5 \%)$ \\
$25-29$ & $5(4.6 \%)$ & $5(7.0 \%)$ \\
$30-34$ & $14(13.4 \%)$ & $6(8.5 \%)$ \\
Over 35 & $29(27.4 \%)$ & $32(45.1 \%)$ \\
Ethnicity & & \\
Asian & $12(11.3 \%)$ & $3(4.2 \%)$ \\
Black & $79(74.5 \%)$ & $62(87.4 \%)$ \\
Mixed race & $8(7.5 \%)$ & $2(2.8 \%)$ \\
Other & $1(1.0 \%)$ & $0(0 \%)$ \\
White & $6(5.7 \%)$ & $4(5.6 \%)$ \\
\hline
\end{tabular}

the academic year (total view time was $27179 \mathrm{~min}$ ). For the 2017-18 cohort, there was a total of 1809 views (total view time was $19461 \mathrm{~min}$ ). Data on the demographic characteristics of viewers were not available. However, university-held data on the student cohorts (see Table 1) showed high proportions of students over 35 years old (2016-17: 27\%; 2017-18: 45\%); female students (2016-17: 92\%; 2017-18: 87\%); and black, Asian and other non-white minority ethnic (BAME) students ( $94 \%$ for both cohorts).

The largest proportion of total views were made using personal computers (20162017: 53.5\%; 2017-2018: 55.8\%). Average views per video were also highest for personal computers in both cohorts (see Table 2). Total view time, average view duration and average proportion of the video viewed were highest for tablets (see Table 2). Figure 1 shows the monthly percentage share of views by device for both cohorts of students during the academic year. For both cohorts, tablets accounted for almost $70 \%$ of views during October, the first month of the academic year. There was a trend of a declining share of views made using tablets throughout the academic year and a corresponding increase in the proportion of views made using personal computers. By the end of both academic years, the proportion of views on tablets was below $30 \%$. For both cohorts, the proportion of views made using personal computers moved above the proportion made using tablets between February and March. Views using mobile phones accounted for a low proportion of views $(\leq 12 \%)$ throughout both academic years, and the proportion of views made on televisions was even smaller $(<5 \%)$.

\section{Discussion}

This study has shown that at the beginning of the academic year, tablets were the preferred device to view video lectures. However, over the course of the academic year, the proportion of views using tablets declined, and personal computers overtook tablets as the predominant device around two-thirds of the way through the academic year. By the end of the academic year, less than $30 \%$ of views were made 
Table 2. Video lecture viewing statistics for 2016-17 and 2018-19 cohorts.

\begin{tabular}{|c|c|c|}
\hline & 2016-2017 Cohort & 2017-2018 Cohort \\
\hline \multicolumn{3}{|l|}{ Total views } \\
\hline All devices & $2813(100 \%)$ & $1809(100 \%)$ \\
\hline Personal computers & $1506(53.5 \%)$ & $1009(55.8 \%)$ \\
\hline Tablets & $1145(40.7 \%)$ & $693(38.3 \%)$ \\
\hline Mobile phone & $161(5.7 \%)$ & $93(5.1 \%)$ \\
\hline Television & $1(<0.1 \%)$ & $14(0.8 \%)$ \\
\hline \multicolumn{3}{|c|}{ Average views per video (range) } \\
\hline All devices & 112 (64 to 217$)$ & 84 (54 to 207$)$ \\
\hline Personal computers & $64(24$ to 135$)$ & $44(21$ to 125$)$ \\
\hline Tablets & $44(32$ to 66$)$ & $36(32$ to 66$)$ \\
\hline Mobile phone & $3(1$ to 9$)$ & $2(1$ to 4$)$ \\
\hline Television & $1(0$ to 3$)$ & $2(0$ to 5$)$ \\
\hline \multicolumn{3}{|l|}{ Total view time (mins) } \\
\hline All devices & $27179(100 \%)$ & $19461(100 \%)$ \\
\hline Personal computers & $8759(32.2 \%)$ & $8739(44.9 \%)$ \\
\hline Tablets & $17218(63.4 \%)$ & $9561(49.1 \%)$ \\
\hline Mobile phone & $1163(4.3 \%)$ & $983(5.1 \%)$ \\
\hline Television & $39(0.1 \%)$ & $178(0.9 \%)$ \\
\hline \multicolumn{3}{|c|}{ Average view duration (mins:secs) } \\
\hline All devices & $9: 37$ & $10: 46$ \\
\hline Personal computers & 7:08 & $9: 34$ \\
\hline Tablets & $11: 49$ & $11: 47$ \\
\hline Mobile phone & $7: 13$ & $10: 34$ \\
\hline Television & $39: 08$ & $12: 42$ \\
\hline \multicolumn{3}{|l|}{ Average $\%$ viewed } \\
\hline All devices & $40 \%$ & $41 \%$ \\
\hline Personal computers & $32 \%$ & $40 \%$ \\
\hline Tablets & $45 \%$ & $44 \%$ \\
\hline Mobile phone & $28 \%$ & $37 \%$ \\
\hline Television & $96 \%$ & $53 \%$ \\
\hline
\end{tabular}

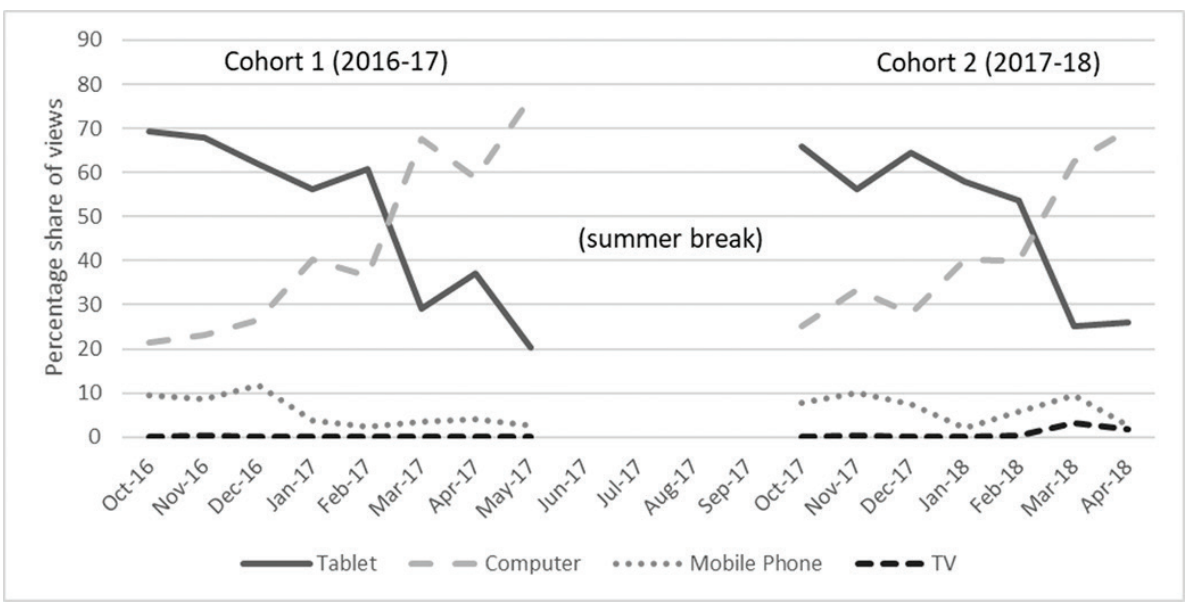

Figure 1. Percentage share of device use to view video lectures during the academic year. 
using tablets. This finding was consistent in two independent cohorts of level 4 students. Results suggest that students have an initial preference for using tablets to view video lectures, but then choose to view using personal computers later in the academic year. One explanation for these findings is that the novelty of a new tablet device is not long-lasting, and tablets become a second choice for viewing video lectures after around 6 months. However, there are several potential alternative explanations for these findings.

The overall proportion of views using tablets was at least $20 \%$ throughout the academic year. This is a considerably higher proportion than reported in any previous studies, where the proportion of views using tablets has been reported to be around 5\% (Delaviz and Ramsay 2018; Gafni and Filin 2015; Gafni and Geri 2015). However, it is likely that higher proportion of views in this study can be explained by the provision of free tablets to all students. The decline in the use of tablets throughout the academic year may indicate that the portability of tablets became less important in influencing students' choice of device. This explanation is supported by the comparatively low proportion of views that were made using mobile phones. The portability of devices such as tablets and mobile phones for mobile learning is often cited as one of their main advantages over personal computers (Schuck, Kearney, and Burden 2017), and the use of mobile phones with the capability to view videos 'on the go' is almost ubiquitous among higher education students (Anshari et al. 2017). However, the findings in this study suggest that device portability was not a major factor in influencing the majority of video lecture views in the second half of the academic year.

The possibility that a decline in tablet use may be due to loss or damage cannot be ruled out, as replacements would not always be provided free of charge to students under these circumstances. However, it is likely that loss or damage of tablets accounts for only a small proportion of the large changes in device usage observed in this study. It is also possible that differences in module activities throughout the academic influenced tablet use. For example, students may be more likely to use personal computers when preparing for assessment in the second half of the year. Personal computers with keyboards tend to be preferred over touchscreen tablets when typing (Kim et al. 2014; Myrberg and Wiberg 2015; Reyal, Zhai, and Kristensson 2015). This preference for personal computers while typing may have influenced the choice of device to view video lectures later in the academic year.

The largest overall proportion of total views and average views per video were made using personal computers. However, total view time, average view duration and average proportion of the video viewed were highest for tablets. This suggests that tablets may be the preferred device when watching videos for a longer period of time. Alternatively, tablets may be the more effective device for maintaining student concentration or attention. These are a limited amount of evidence to suggest that mobile device use may impact attention and concentration (Wilmer et al. 2017), but no previous studies have examined how device choice can influence concentration and attention. There is a need for primary research in this area to examine the impact of device choice on students' concentration and attention when viewing video lectures and participating in other learning activities.

The main strengths of this study are the use of data on two separate cohorts of students with data on over 4500 views of video lectures. Furthermore, this study uses data on students who had access to both tablets and personal computers throughout the academic year, making the results more robust to potential confounding by socio-economic and demographic characteristics. To the authors' knowledge, this 
study is unique in that device choice for viewing video lectures could be studied when students had continuous access to both tablets and personal computers.

The study also has some limitations. Data on individual users are not available through YouTube Analytics, so it cannot be determined if some students moved entirely from tablet use to personal computer use (or vice versa). Furthermore, data on unique views were not available through YouTube analytics at the time of this study. It was not possible to collect data beyond level 4 as video lectures were not used in a level 5 module for these cohorts. Further research is needed to examine whether the trend in device use continues into the second and third years of study, or if the preference for tablet use at the beginning of the academic year is repeated at levels 5 and 6 .

The findings of this study may not be generalisable to the whole student population. Demographic data were not collected as part of this study. However, the data on video lecture views come from a cohort of students with higher proportion of mature, female and BAME students when compared with national student demographic profiles. Different student populations have different learning needs and preferences (Robinson and Stubberud 2012), and previous research has shown that device preferences for listening to podcasts for learning differ between student groups (Anderson 2011; Robinson and Stubberud 2012). The higher proportion of students aged over 35 years in the two student cohorts may have influenced results. For example, Prensky (2001) suggest that older learners may tend to be initially enthusiastic to engage with technology which is new to them, such as tablets. However, older learners are also more likely to become frustrated with new technology more quickly and require sustained technical support if the use of new technology is to become embedded. Further research is needed to establish the generalisability of this research to other student populations.

The evidence base on device choice would benefit from future research where data on individual students are available over consecutive years of study, to identify trends throughout the duration of a programme. Further data with greater variation in the subject content of videos (e.g. across different modules or programmes of study) and with greater variation in the length of videos may provide useful information to enable educators to optimise videos for viewing on specific devices. There is also a need for studies on device preference across a broader range of purposes, including e-books, virtual learning environments, communication and apps to support learning. For example, studies have shown that students tend to prefer hard copies of text books over e-books on tablets or personal computers (Myrberg and Wiberg 2015; Palilonis and Bolchini, 2015; Ross et al. 2017). However, as e-books have become more pervasive, little is currently known about device preferences for students using e-books and how device choice may impact on their learning experiences and performance. The objective use of data collected using YouTube Analytics is a strength of this study; however, there may be opportunities in future research to supplement these data with feedback provided by students on factors influencing their choice of device when they view a video lecture. Finally, qualitative research may help to provide a more in-depth understanding of HEI students' experiences of tablet use throughout the academic year and help to explain mechanisms behind the observed decline in tablet use throughout the academic year.

\section{Conclusion}

In this study, the choice of device to view video lectures was monitored objectively in two independent cohorts. The main finding of this study was that use of 
tablets declined and use of personal computers increased throughout the academic year for both cohorts. There is evidence in this study to suggest that the initial novelty of tablets to view video lectures appears to last only for a few months, with personal computers being the preferred device to use by the end of the academic year. These findings may be explained by the limited functionality of tablets for other purposes. This evidence should be taken into account when considering initiatives to provide large numbers of students with new technology such as tablets.

\section{Acknowledgements}

The authors would like to thank the students who participated in module activities, including the views of video lectures that made this research possible.

\section{References}

Anderson, L. (2011) 'Podcasting, cognitive theory, and really simple syndication: what is the potential impact. When used together?', Journal of Educational Multimedia and Hypermedia, vol. 20, no. 3, pp. 219-234.

Anshari, M., et al., (2017) 'Smartphones usage in the classrooms: learning aid or interference?', Education and Information Technologies, vol. 22, no. 6, pp. 3063-3079. doi: 10.1007/ s10639-017-9572-7

Brecht, H. D. \& Ogilby, S. M. (2008) 'Enabling a comprehensive teaching strategy: video lectures', Journal of Information Technology Education, vol. 7. pp. 71-86. doi: 10.28945/198

Byrne-Davis, L., et al., (2015) 'Just-in-time research: a call to arms for research into mobile technologies in higher education', Research in Learning Technology, vol. 23, p. 25653. doi: 10.3402/rlt.v23.25653

Coughlan, S. (2014, September 25) 'University gives free tablet computer to new students', [online] Available at: https://www.bbc.co.uk/news/education-29346992

Delaviz, Y. \& Ramsay, S. D. (2018) 'Student usage of short online single-topic videos in a first-year engineering chemistry class', Proceedings of the Canadian Engineering Education Association (CEEA), vol. 141, pp. 1-4.

Fabian, K. \& MacLean, D. (2014) 'Keep taking the tablets? Assessing the use of tablet devices in learning and teaching activities in the further education sector', Research in Learning Technology, vol. 22, p. 22648. doi: 10.3402/rlt.v22.22648

Gafni, R. \& Filin, D. (2015) 'Worldwide video use patterns in e-learning: exploring time, completion rate, and devices', Online Journal of Applied Knowledge Management, vol. 3, no. 1, pp. 74-92.

Gafni, R. \& Geri, N. (2015) 'Evolving consumption patterns of various information media via handheld mobile devices', Issues in Informing Science and Information Technology, vol. 12, pp. 83-93. doi: 10.28945/2259

Giannakos, M. N. (2013) 'Exploring the video-based learning research: a review of the literature', British Journal of Educational Technology, vol. 44, no. 6, pp. E191-E195. doi: 10.1111/bjet.12070

Giannakos, M. N., Chorianopoulos, K. \& Chrisochoides, N. (2015) 'Making sense of video analytics: lessons learned from clickstream interactions, attitudes, and learning outcome in a video-assisted course', The International Review of Research in Open and Distributed Learning, vol. 16, no. 1, pp. 260-283. doi: 10.19173/irrodl.v16i1.1976

Giannakos, M. N., Jaccheri, L. \& Krogstie, J. (2016) 'Exploring the relationship between video lecture usage patterns and students' attitudes', British Journal of Educational Technology, vol. 47, no. 6, pp. 1259-1275. doi: 10.1111/bjet.12313 


\section{J. Namuddu and P.N. Watts}

Google. (2014, August 20) 'YouTube analytics and reporting APIs', [online] Available at: https://developers.google.com/youtube/analytics/

Herala, A., et al., (2017) 'Experiences from video lectures in software engineering education', International Journal of Modern Education and Computer Science, vol. 9, no. 5, p. 17. doi: 10.5815/ijmecs.2017.05.03

Henderson, M., Selwyn, N. \& Aston, R. (2017) 'What works and why? Student perceptions of "useful" digital technology in university teaching and learning', Studies in Higher Education, vol. 42, no. 8, pp. 1567-1579. doi: 10.1080/03075079.2015.1007946

Kennedy, G. E., et al., (2008) 'First year students' experiences with technology: are they really digital natives?', Australasian Journal of Educational Technology, vol. 24, no. 1, pp. 108-122. doi: 10.14742/ajet.1233

Kinash, S., Brand, J. \& Mathew, T. (2012) 'Challenging mobile learning discourse through research: student perceptions of blackboard mobile learn and iPads', Australasian Journal of Educational Technology, vol. 28, no. 4, pp. 639-655. doi: 10.14742/ajet.832

Kim, J. H., et al., (2014) 'Differences in typing forces, muscle activity, comfort, and typing performance among virtual, notebook, and desktop keyboards', Applied Ergonomics, vol. 45, no. 6, pp. 1406-1413. doi: 10.1016/j.apergo.2014.04.001

Miner, S. \& Stefaniak, J. E. (2018) 'Learning via video in higher education: an exploration of instructor and student perceptions', Journal of University Teaching and Learning Practice, vol. 15 , no. 2, p. 2. doi: $10.28945 / 4111$

Myrberg, C. \& Wiberg, N. (2015) 'Screen vs. paper: what is the difference for reading and learning?', Insights, vol. 28, no. 2, pp. 49-54. doi: 10.1629/uksg.236

O'Bannon, B. W., et al., (2011) 'Using podcasts to replace lecture: effects on student achievement', Computers \& Education, vol. 57, no. 3, pp. 1885-1892. doi: 10.1016/j. compedu.2011.04.001

O'Flaherty, J. \& Phillips, C. (2015) 'The use of flipped classrooms in higher education: a scoping review', The internet and Higher Education, vol. 25, pp. 85-95. doi: 10.1016/j. iheduc.2015.02.002

Palilonis, J. \& Bolchini, D. (2015) 'Active reading behaviors in tablet-based learning', Journal of Educational Multimedia and Hypermedia, vol. 24, no. 3, pp. 235-261. doi: $10.1108 / 10748120110424816$

Prensky, M. (2001) 'Digital natives, digital immigrants part 1', On the Horizon, vol. 9, no. 5, pp. 1-6. doi: 10.1108/10748120110424816

Reyal, S., Zhai, S. \& Kristensson, P. O. (2015, April) 'Performance and user experience of touchscreen and gesture keyboards in a lab setting and in the wild', Proceedings of the 33rd Annual ACM Conference on Human Factors in Computing Systems, ACM, New York, pp. 679-688. doi: 10.1145/2702123.2702597

Robinson, S. \& Stubberud, H. A. (2011) 'Student communication preferences for work/school and social purposes', Academy of Educational Leadership, Columbus, OH, p. 55.

Robinson, S. \& Stubberud, H. A. (2012) 'Student choice of course materials', Allied Academies International Conference. Academy of Educational Leadership, Columbus, OH, p. 41.

Ross, B., et al., (2017) 'Print versus digital texts: understanding the experimental research and challenging the dichotomies', Research in Learning Technology, vol. 25. doi: 10.25304/rlt. v25.1976

Scagnoli, N. I., Choo, J. \& Tian, J. (2017) 'Students' insights on the use of video lectures in online classes', British Journal of Educational Technology, pp. 339-414. doi: 10.1111/bjet.12572

Schuck, S., Kearney, M. \& Burden, K. (2017) 'Exploring mobile learning in the third space', Technology, Pedagogy and Education, vol. 26, no. 2, pp. 121-137. doi: 10.1080/ 1475939X.2016.1230555

Vogt, M., et al., (2010) 'The impact of podcasting on the learning and satisfaction of undergraduate nursing students', Nurse Education in Practice, vol. 10, no. 1, pp. 38-42. doi: 10.1016/j.nepr.2009.03.006 
Walls, S. M., et al., (2010) 'Podcasting in education: are students as ready and eager as we think they are?', Computers \& Education, vol. 54, no. 2, pp. 371-378. doi: 10.1016/j. compedu.2009.08.018

Wilmer, H. H., Sherman, L. E. \& Chein, J. M. (2017) 'Smartphones and cognition: a review of research exploring the links between mobile technology habits and cognitive functioning', Frontiers in Psychology, vol. 8, p. 605. doi: 10.3389/fpsyg.2017.00605 